\title{
Online Learning for Mass Audiences during the COVID-19 Pandemic: Key Considerations for Real Time Knowledge Transfer
}

https://doi.org/10.3991/ijet.v17i04.27569

Heini Utunen( $\left.{ }^{\bowtie}\right)$, Anna Tokar, Elham Arabi, Gaya M Gamhewage

WHO Health Emegencies Program, Organization Mondiale de la Santé, Genève, Suisse

utunenhewho. int

\begin{abstract}
This paper introduces online learning related key considerations for asynchronous health information dissemination during the COVID-19 pandemic. The findings are based on 1.5 years of real-time massive scale learning intervention during this public health emergency and on related literature reviews. Meta-data analysis on World Health Organization's (WHO) open access online learning platform OpenWHO and review on health emergency learning interventions literature. The study sought to operationalize the key considerations related to the health information dissemination as an asynchronous online learning delivery. Statistics driven findings were made based on open-source learning platform OpenWHO use case and scientific literature from the similar recorded experiences. The paper presents analysis from the recent literature and couples it with the real-time pandemic learning response results. The study suggests establishing key considerations for health emergency related learning dissemination for mass audiences: Real-time learning provision in free access, low-bandwidth and offline use formats, national and local language provision, choice of format for learners and adjustment of the learning content based on adult learning principles. The key considerations of the online learning delivery in mass mode in health emergencies emerged from the study and are recommended way forward for any international learning provided in health emergencies.
\end{abstract}

Keywords-massive open online courses, online learning, COVID-19 pandemic, World Health Organization 


\section{Introduction}

When reports of the novel coronavirus emerged in January 2020, World Health Organization's (WHO) OpenWHO online learning platform team sprang into action, relying on its 2.5 years of prior experience in real-time learning response to health emergencies. The pandemic learning response of the WHO was channeled through transferring real-time knowledge for COVID-19 through WHO's free online learning platform OpenWHO.org.

Asynchronous, self-paced learning intervention that is not bound to time or place deemed to be the feasible option to reach to mass audiences as physical contact were halted by lockdowns, meeting and travel restrictions and closures of schools and nonessential services in many parts of the world. WHO experts helped the OpenWHO team to adapt existing WHO evidence on the novel coronavirus (later named COVID19) and guidance on managing severe acute respiratory pathogens into learning courses [4].Course production accelerated as the first WHO Emergency Committee meeting took place 22-23 January 2020 and, fulfilling the requirements of WHO's Emergency Response Framework, the first learning resource was put together over the next 72 hours and launched in open-source format on 26 January 2020. This took place before a Public Health Emergency of International Concern (PHEIC) was declared on 30 January 2020. Since January 2020, the OpenWHO team has transferred essential knowledge for managing the COVID-19 pandemic to frontline responders, decisionmakers and the public in a mass delivery mode [5].

The primary goal of this research is to explore key enabling factors that contribute to the equitable learning experience for mass audiences. This research also aims to determine which online practices drive the reach in the global information dissemination context. In particular, the current study aims to pinpoint specific online learning strategies as evidenced in the related literature. Additionally, the documented and data driven knowledge transfer work on OpenWHO platform informs the operational side of work.

Finally, this project should be considered as a live example of how evidence-based information collected by the literature review in 2020 (Phase 1) informed practical implications and confirmed decisions employed on the OpenWHO platform (Phase 2).

\section{$2 \quad$ Methods}

This descriptive study is comprised of a literature review focusing on online learning in public health and online learning and COVID-19 pandemic and of a component analyzing OpenWHO user metrics on OpenWHO platform over the 15 months of pandemic response. 
Paper - Online Learning for Mass Audiences during the COVID-19 Pandemic: Key Considerations for...

\subsection{Research questions}

1. What are the key enabling factors, means and values for equitable and global learning information dissemination for mass audiences during the COVID-19 pandemic?

2. What online practices should be put in place to drive the reach and ensure access in the global information dissemination context?

\subsection{Phase 1: Literature review: Study design, data collection and analysis}

A literature review was carried out using search terms identified within three key concepts: Online learning, Public Health and COVID-19 pandemic. Key terms were searched using a free text strategy in the titles and abstracts. Databases searched included the Cochrane Database of Systematic Reviews, the Campbell Collaboration Database of Systematic Reviews, GIFT/HINARI, PubMed/MedLine, and the Wiley Online Library. Databases were searched using predefined combinations of key terms. Articles were published between 2008 - 2021. There were also separately identified four papers included from 2021.

All identified references were imported into the bibliographic management software ENDNOTE X7- with exception of the GIFT/HINARI database and the Campbell Collaboration Database of Systematic Reviews were extracted as text files. A total of 36 research papers fulfilled the inclusion criteria and were reviewed using a standardized form that included information on the period of study, location, study sample and design, research questions/aim and objectives, key findings, and conclusions.

\subsection{Phase 2: OpenWHO study design, data collection and analysis}

The project employed a descriptive study design, which included analysis of the OpenWHO user data. The OpenWHO user metrics included parameters related to location, gender, language, age, and affiliation of users. Anonymized statistical datasets were obtained from the OpenWHO integrated reporting system, providing platform-wide, topical and course-specific and language version datasets (1-9). Additionally, durations of the web-sessions and learner behavior on the platform were captured in the platform data. Moreover, course users' OpenWHO activity by geographic location was captured by Google Analytics. Selected use cases from the platform data were explored in order to investigate user groups, use of languages, general metrics, etc. Overall, the data were collected from January 2020 to March 2021 with data over the 15 months of pandemic response and included data of 2285446 million users, 5 090545 million course enrolments from 194 countries.

Data were analyzed using Power BI to present descriptive statistics. Several platform course survey data are referred to. Variables of interest included those describing socio-demographic information of the OpenWHO users' location, gender, language, age and affiliation as well as users' learning behavior and motivation. We also 
presented data on users' learning behavior. Users' learning behavior was captured by the duration of the web sessions, with "an active session" defined as the period when a user actively engaged with the OpenWHO platform.

Departing from the findings of literature review and informed by analysis of imperial data of OpenWHO, we summarized available evidence to inform selected key considerations for asynchronous learning dissemination during a health emergency of largest scale, the pandemic.

\section{$3 \quad$ Results}

\subsection{Phase 1 results: Overview of the examined literature}

The 36 articles were organized into three main categories:

- COVID-19 (N=19)

- Online learning $(\mathrm{N}=15)$

- Learning transfer $(\mathrm{N}=2)$

Out of 36 studies retained for analysis, most were reviews and/or systematic reviews $(\mathrm{N}=11)$, followed by commentaries $(\mathrm{N}=9)$. Five papers used quantitative methods, four a mixed-method approach and quantitative methods, and three studies applied qualitative design. Most of the papers reported work conducted at the global level $(\mathrm{N}=20)$, seven in North America, four in Europe, three in Asia and two in Africa.

Influence of COVID-19 pandemic on learning and knowledge transfer. The COVID-19 pandemic caused in-person training around the world to shut down, thus highlighting the urgent necessity for alternative approaches and channels for education, not only for health professionals, but also for the general population. In total, five studies examined this topic [8, 10, 24-29] as well as identified a number of blogs, opinion papers, communications and one ahead-of-print publication [7, 8, 30-40]. At last, out of all studies retained for review, two of them aimed to examine learning transfer [41, 42].

The literature reported on how the current COVID-19 crisis could be seen as a "black swan moment" on the training of health professionals, and the role of digital learning in particular [24-26]. Selected studies discussed the role of correct, timely and accessible information during COVID-19 pandemic [24-26, 40]. Aldohyan and colleagues argued that the focus of current learning strategies should not be made on the content of materials, but on the accessibility and structure of educational materials [24]. They suggested that instructors may not necessarily face the difficulties in producing new information, as an immense amount of valuable information already exists in the literature, yet the problem arises from the fact that current knowledge is either poorly structured or inaccessible to health care professionals. In this regard, it was recommended to consider a new concept of "knowledge brokers", who may act as disseminators of knowledge among a certain group of health professionals (e.g. the nursing body), and thus, may facilitate knowledge translation by retrieving different 
types of evidence, synthesizing it in different forms, translating it by evaluation, interpreting it and then distributing it [24].

Health professionals might experience some sort of "fatigue" or "tolerance" because of repetitive exposure to MERS-CoV education and campaigns, and thus interactive activities are recommended. Hence, negative perception of knowledge transfer might be due to a pre-existing lack of trust in the media or in websites that might, to some degree, lack scientific credibility in comparison with educational programmes provided in health care centres [24, 40]. Fernandez-Diaz and colleagues argued that during health crisis situations, such as COVID-19, communication must be understandable and accessible by all types of people, regardless of their technology, language, culture or disability (physical or mental) [25]. Also, colour vision deficiency should be also taken into consideration when creating accessible web content [25]. Overall, authors called for "web accessibility for all", providing that digital education platforms should offer text alternatives for non-text content, especially for people with vision impairment who use screen readers $[25,26]$.

Chick and colleagues, examining how the educational landscape for surgical residents should be changed during the pandemic, suggested considering several innovative solutions including the flipped classroom model, online practice questions, teleconferencing in place of in-person lectures, involving residents in telemedicine clinics, procedural simulation, and the facilitated use of surgical videos Guidelines 2.1[26]. In the Journal of Educational Change Zhao and Watterson [7] argued that the pandemic has created a unique opportunity for educational changes proposed before COVID-19 but never fully recognized. They identified three big changes to the education for post COVID: (a) curriculum that is developmental, personalized, and evolving; (b) pedagogy that is student-centered, inquiry-based, authentic, and purposeful; and (c) delivery of instruction that capitalizes on the strengths of both synchronous and asynchronous learning. This echoes what we have learnt and experienced in WHO.

Recent literature shows that COVID-crisis has created a new reality, changing the way of how our life used to be conducted. This also implies that social processes are changing now and will change more in the future. In this regard, studies discussed a major shift toward online learning approaches as well as urgent necessity not only to educate and engage health care professionals, but also communities [24-27]. Thus, the social value of knowledge translation might be considered, where a social value cocreation perspective incorporating the interests of multiple actors can be used [31]. This also might contribute to the validation of knowledge transfer as different actors involved in the process of its co-creation will develop ownership. It is worth mentioning that there are aged-based and context differences on how people locate COVID19 news and information. It was demonstrated that the WHO's social media channels were the most popular among people aged 18-40 years in India, Mexico, and Nigeria while in Egypt, Indonesia, Russia, and South Korea, search platforms were preferred [8].

Evidence suggested that peer educators, drawing on the credibility which they have among people in their social network and leveraging the power of a role model, might be an important building block of learning approach during COVID-19 [24]. There- 
fore, dynamics within different networks and communities of learning should be considered. Additionally, an online tool to validate health information might be considered. Finally, while there is a certain polarization of current debates on digital and traditional learning in health care education, one might argue for a more holistic standpoint trying to marry these concepts and take the best of both to meet the needs of local communities and contexts. Overall, using a divisive pluralistic approach, intended to contrast and compare digital and traditional learning might not necessarily indicate their strengths and weaknesses or how to build on them. However, newly appeared proponents and opponents of these two learning modes inadvertently clash, bringing the agenda away from collaboration and creation of a novel strategy incorporating ideas of online learning as well as a traditional learning approach.

\section{Online learning as an enabler}

Effectiveness. Learning effectiveness is presented based on twelve studies reported on effectiveness of digital learning, including all systematic reviews, which assessed online learning approaches in the areas listed below: technology-enabled knowledge translation strategies (TEKT) to increase use of research in public health [43]; digital education on chronic wound management [44]; artificial intelligence (AI), and diagnostic deep learning algorithms for medical imaging [45]; enablers, and barriers of $\mathrm{e}^{-}$learning in health sciences education [46]; cloud technology adoption in health sector[47]; digital education on clinical practice guidelines [48]; digital undergraduate education in dentistry [27]; and e-learning programmes in licensed health professionals [49]. Additionally, four quantitative, and one qualitative studies examined effectiveness of such digital activities: e-learning programme focusing on improving health care professionals' attitudes, and practices on breastfeeding [52]; e-learning course on child protection in medicine [53]; utilization of virtual worlds as a platform for collaborative meetings in health care [50]; and a massive online open course on implementation research for learners in low- and middle-income countries [9].

We observed a high diversity of outcome measures, and period of observation applied in relation to effectiveness. For example, most studies examined changes in the knowledge level of health professionals over time, yet study design varied from a cross $^{-}$sectional with a pre- and post-test assessments (i.e. testing before and after learning activity) [53] to a longitudinal approach, where knowledge retention up to six months or a one-year follow up was carried out [52]. Consequently, these inconsistencies may lead to equivocal results demonstrated by authors. It is also suggested to consider the nature of the discipline as digital learning might be more effective in certain domains of public health and medicine, while it might not be as effective in others.

Four systematic reviews demonstrated that digital learning approaches may be effective in improving the knowledge of public health professionals [43, 44, 48, 49]. In three articles, digital learning approaches were claimed to be more effective than no intervention in improving knowledge [43, 44, 48] or at least as effective as traditional learning [48]; yet one systematic review suggested that e- learning may make little or no difference in patient outcomes or health professionals' behaviours, skills or knowledge [49]. Moreover, knowledge level was also examined by two crosssectional studies conducted in Germany, and Italy, one case study in Portugal, and 
one evaluation of a massive open online course (MOOC) [9, 52-54]. Authors reported an improvement of knowledge level $[53,54]$ as well as participants of these interventions reported utilization of the knowledge [31], and skills gained in their professional lives frequently [9]. Previous research on the effectiveness of digital learning for knowledge acquisition in health professionals confirmed that either online or blended learning had a more consistent positive effect than no intervention or traditional learning [17-20]. However, findings indicated that instructional strategies had an impact on the provision of effective learning regardless of the mode of delivery as there is no 'one-size-fits-all' approach to optimizing outcome measures [17-21].

Maier and colleagues, when assessing effectiveness of an online course, described how attitudes, and practices regarding the protection, promotion, and support of breastfeeding were higher immediately after training, but decreased over time [52]. The evidence suggests that to maintain transfer of learning after training and avoid skill decay learners should be able to use what they learned, receive timely constructive feedback, and refresh their learning through job aids or retraining [56, 57]. Research on training transfer indicates that factors such as work environment (i.e., supervisor or peer support), trainee characteristics (i.e., motivation and self-efficacy), and training design can affect retention and transfer of acquired knowledge and skills [11-16]. Salas and colleagues contend that retention of learned material and assessment of transfer should be targeted for training evaluation using rigorous methods for collecting such data $[56,57]$.

Many authors argued that there is a need to establish generally accepted digital standards of education to provide effective learning and consider collecting data on the cost-effectiveness or cost-benefit of digital learning approaches. Previous studies comparing cost-effectiveness of digital and traditional learning indicated that both online and blended learning were found to be more cost-effective than traditional instruction; nonetheless, the cost-benefit of these modes of delivery could not be determined without more rigorous data [22, 23].

Evidence from several systematic reviews have shown that these approaches are more effective in the knowledge level of public health professionals if compared to no intervention or are at least as effective as traditional learning in improving learners' outcomes. These findings might be especially important in situations, such as a pandemic, when the ability to employ traditional or blended learning approaches is limited.

Accessibility, availability and feasibility. We reviewed nine articles which examined different aspects of accessibility, availability, and feasibility of digital learning, including: costs (time restraints, faculty, and transport costs), needed participants' baseline computer skills (digital literacy), equipment, personalization, student-centred learning, interactivity, ease of use, continuity and digital inclusion $[9,27,36,44,46$, $47,50,54,55]$.

Digital approaches were more intuitive, interactive and facilitated continuous participation of students through their own dynamics [27] or even to lifelong learning [46]. Thus, one study indicated that e-learning could meet lifelong education needs, as well as widening participation in achieving desired learners' outcomes in practice, as e-learning approaches were often context-specific [46]. Furthermore, it was argued 
that digital learning allowed students to work at their own pace, and thus, was by nature more flexible, self-directive and inclusive [27, 44, 46, 54]. Participants were able to revisit learning materials at any time, and from anywhere they liked, using multiple tools promoting interactions with their colleagues. Moreover, digital learning might be an alternative avenue to educate the adult population without having to make them choose between their professional and family lives or going back to university to improve their knowledge and self-confidence [27, 44, 46, 54].

Zitzmann and colleagues, in the systematic review on digital learning in dentistry, suggested that students today, particularly the millennials, expect learning materials to be instantly and always available, including their grades, course schedules, and other information to be generated automatically 24/7 [27]. In this regard, not only elearning should be considered as an alternative way to meet the current needs of students and health professionals, but e-teaching should also be taken into account as it also requires a certain shift of pre-existing pedagogical paradigm, and a change of mindset of the faculty (trainers) as well to enable theoretical, and practical knowledge transfer [36, 54].

Data demonstrated that some people might feel more comfortable, and less nervous as online approaches created a learning environment in which immediate digital evaluation and feedback were provided [27, 50].This together with self-evaluation and self-correction might improve students' knowledge and enhance instructor evaluation $[27,50]$. Taylor and colleagues illustrated how the utilization of virtual worlds for meetings could help people who experience anxiety when meeting face-to-face to gain confidence and be more vocal [50]. Still, personal instruction and feedback from faculty (instructors) cannot be replaced by digital feedback only, especially when supervising students (trainees) during patient treatment in clinical courses which is why the role model function of faculty (instructors) is important [27].

Three studies discussed in detail which elements of digital learning should be improved and how [27, 47, 51]. Sadeghi and colleagues reported on how the adoption of cloud technology may facilitate digital learning, as it may be perceived of easier to use, of higher security and confidentiality, which can be easily explained by the growth in the utilizations of tablets and smartphones [47]. Furthermore, Zitzmann and colleagues suggested that replacing scripts with pictograms in educational videos for undergraduate dentistry students may facilitate a language-independent application in several countries and thus, may save time [27]. Nugroho and colleagues described a new method for selecting elements in order to improve current e-learning strategies using the Difficulty-Usefulness Pyramid with Weighting (DUP-We), namely: learning design, handout book, links to resources, discussion, chat, assignment, feedback, quiz and survey. The authors found that to improve e-learning in health, the assignment was the first element to be prioritized, followed by: quiz, feedback, discussion, link to resources, books, surveys, learning design, handouts, and chat. It was also recommended to handle the five elements listed below first: assessment, quiz, feedback, discussion and link to resources [51].

Seven studies reported on how digital learning saved costs, including: time of both trainers and trainees, transport costs (which may depend on distance to learning centres), number of faculty involved, and needed spaces $[9,27,44,50,54,55]$. These 
approaches required a certain baseline level of computer skills, equipment, and access to the Internet, which might serve as a barrier for participants from low- and middleincome countries or certain populations (e.g., refugees or people with vision problems) $[9,25,55]$. Participants' baseline computer skills (digital literacy) were a significant factor which either could impede or facilitate adoption of digital learning [47, $50,55]$. For example, in Kenya, it was shown that access to blended learning allowed participants to build on their technical capacity, which then contributed to the professional health workforce in Dadaab, as obtaining computer skills enabled participants to not only access education but also job markets [55].

Whereas the feasibility, accessibility, and other aspects of digital learning may contribute to effective learning, it is important to consider the advantages and barriers of digital learning in conjunction to determine desired results, in particular knowledge transfer and knowledge translation. It was gathered from the reviewed papers that there are several enablers and barriers of digital learning. Table 1 illustrates the list of enablers and barriers of digital learning approach.

In conclusion, online leaning breaks paradigms, brings innovation and new perceptions in pedagogy, and by doing so facilitates an alternative process of teaching and learning. For example, Carapeto and colleagues shared their successful experience of the nutrition and health course implementation and reported how this approach created new meaning in the relationship between teacher and student, especially in the teaching and learning process as the pedagogical dynamics were coordinated with the new technologies [54]. Overall, digital learning offers a suitable alternative to deliver knowledge to health care professionals who may not be able to access them otherwise, due to workload, distance from learning centres (transport), and other costs [44]. Finally, we argue that the positive effects of digital learning are diverse, and they may involve different spheres of life and work of learners. Learners' gains might involve direct short-term results and learners' needs could be addressed (e.g. improved level of knowledge). Further, as literature has shown, it may include beneficiary secondhand effects and meet broader long-term learners' needs (e.g. adoption of computer skills, which may assist in job search or promotion). Therefore, a more nuanced understanding of digital approaches and their impact on learner's lives is needed. 
Table 1. Enablers and barriers of digital learning approach

\begin{tabular}{|c|c|}
\hline Enablers & Barriers \\
\hline $\begin{array}{l}\text { Costs saving }[9,27,44,50,54,55] \\
\text { Intuitive; Perceived ease of use for people with higher } \\
\text { digital literacy [27,46,50,51]; } \\
\text { Flexibility; Materials could be accessed } 24 / 7 \text {, helpful } \\
\text { for revisions and exams }[27,46] \text {; } \\
\text { Adaptivity; Providing students more choices in terms } \\
\text { of the place and pace, adjusted to learners' rhythm } \\
\text { (self-directive, self-regulation, autonomy, and account- } \\
\text { ability) of learning experiences [46]; } \\
\text { Continuous participation [27] or lifelong learning [ } 46] \text {; } \\
\text { Inclusive; Meeting persistent needs of different popula- } \\
\text { tions (working adults, [27, } 44,46,54] \text { people who are } \\
\text { nervous when meeting face-to-face, [50] millennials } \\
\text { [27]); } \\
\text { Learners at the center of pedagogy [46]; } \\
\text { Contextualized [46]; } \\
\text { Reflective thinking, self-confidence and satisfaction } \\
\text { [46]. }\end{array}$ & $\begin{array}{l}\text { Digital literacy and technical capacity }[47,50,55] \text {; } \\
\text { Internet access and quality of Internet connection and } \\
\text { other technical difficulties }[9,46,55] \text {; } \\
\text { Time and resources needed to train people (learners and } \\
\text { instructors) }[9,55] \text {; } \\
\text { Potential isolation; No real-life relationships with peers } \\
\text { and tutors. Lack of non-verbal communication; Poor } \\
\text { support }[46,50] \text {; } \\
\text { Language barriers [46]; } \\
\text { Vision problems of learners [25]; } \\
\text { Poor integration of e-learning in practice, existing aca- } \\
\text { demic curriculum and professional education [46]; } \\
\text { Self-discipline and technology-phobia [46]. }\end{array}$ \\
\hline
\end{tabular}

\subsection{Phase 2 results: Informed by OpenWHO data}

OpenWHO provides easy and open access to knowledge for frontline responders and the general public to fight the COVID-19 pandemic. The platform was designed with the global pandemic as the planning proxy. It has contributed to knowledge transfer for health emergency events since 2017 to prevent avoidable death, disease, disability and damage to societies and economies. The pandemic learning response started in January 2020, soon the unknown pathogen investigation and response was mounted at the WHO and in the member states.

Influence of COVID-19 pandemic to online learning on OpenWHO. As the COVID-19 pandemic surged, new learners joined the OpenWHO platform in a heavy upward surge. Total enrolments increased from 160000 in January 2020 to 5.8 million in October 2021. OpenWHO published 38 COVID-19 courses covering a variety of topics from vaccination, infection prevention and control to risk assessment for mass gatherings and treatment facility design among other topics. Courses are updated as new guidance and tools become available. The courses are available in 58 languages and counting, including the 15 most-spoken languages of the world and 27 languages selected to reach vulnerable populations who may lack access to trusted information about the pandemic. Forty-two of the languages spoken in the 46 least developed countries are featured in the platform. The steep scale-up of online platform use of self-paced courses made available during the COVID-19 made OpenWHO become WHO's largest online learning platform by enrolments. $82.51 \%$ of all enrolments were on COVID-19 topics, making the pandemic the reason for the platform enrolment growth. 


\section{Online learning as experienced on OpenWHO}

Effectiveness. When examining the effectiveness of the knowledge transfer through online learning, OpenWHO has experienced not only massive increase in the enrolments, but also a steady increase in a) attendance to the courses, b) course completion rates and c) improved levels of knowledge retained. Nonetheless, it was observed that the attendance rate is the most prominent during the first four weeks following each course launch where after it gradually decreased over time.

First, as of March 2021 OpenWHO data, a total 2285446 unique learners had joined the platform, contributing to a total of 5090545 enrolments. This calculates into average 2 courses attended by each learner. $52 \%$ of the learners only took one course. On the other hand, there were 75105 learners who had completed more than 10 courses on the platform (Figure 1). A badge system recognizing the achievements was launched on the platform to generate badges for the users.

\begin{tabular}{|c|r|r|}
\hline $\begin{array}{c}\text { No. of } \\
\text { courses }\end{array}$ & $\begin{array}{c}\text { No. of } \\
\text { users }\end{array}$ & $\%$ of GT \\
\hline 1 & 1012976 & $52 \%$ \\
\hline 2 & 434854 & $22 \%$ \\
\hline 3 & 200203 & $10 \%$ \\
\hline 4 & 98895 & $5 \%$ \\
\hline 5 & 55796 & $3 \%$ \\
\hline 6 & 33428 & $2 \%$ \\
\hline 7 & 21525 & $1 \%$ \\
\hline 8 & 15239 & $1 \%$ \\
\hline 9 & 11090 & $1 \%$ \\
\hline $10+$ & 75105 & $4 \%$ \\
\hline
\end{tabular}

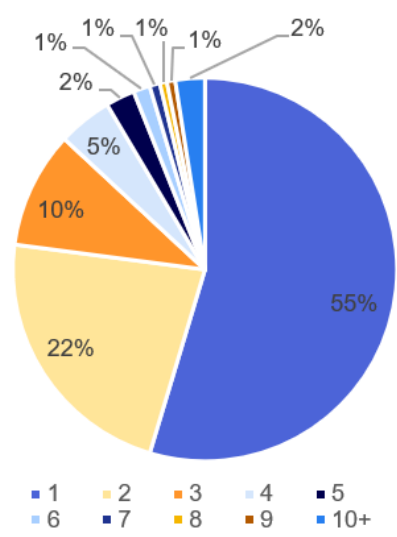

Fig. 1. Number of courses completed by users on OpenWHO

Second, the platform has issued more than 2.8 million certificates. Half of them were for Completion of Participation (CoP), a certificate that is generated when $80 \%$ of the learning content of the course is completed. Half of the certificates were for the Record of Achievement (RoA) that testifies the learning content and the end of course assessments have both been completed at least at the level of $80 \%$.

Average completion rate on OpenWHO increased from $39.19 \%$ before the pandemic time (December 2019) to 54.19\% in March 2021. Some courses hit very high completion rates, such as the health worker vaccine course in Spanish, $89 \%$ and Ebola GO pre-deployment course, $94 \%$.

Lastly, following the outcome measures such as the knowledge increase and learning retention, recent evidence from the health worker vaccine course pre- and posttest results [63] informed on the increased knowledge retained from before the course to the course completion stage.

Exploring the effectiveness of other aspects than the learning outcomes and retention, OpenWHO did not have prior precedent to measure and report on cost effectiveness or contribute to the cost-benefit analysis. Further, OpenWHO has not been part 
of any certification system and this also will be explored in the future, along with the WHO corporate directions in the learning domain. Also, the impact of the factors from the environment [11-16] has not been largely explored on OpenWHO.

Accessibility, availability, feasibility. OpenWHO generated data from the platform use case to inform the WHO as the learning provider on the aspects for equitable and enabling knowledge transfer and information dissemination. In terms of access and reach, the platform proved to be accessible everywhere in the world. The platform has been used in all 194 member states as per the recent World Health Assembly 2021 map (Figure 2).

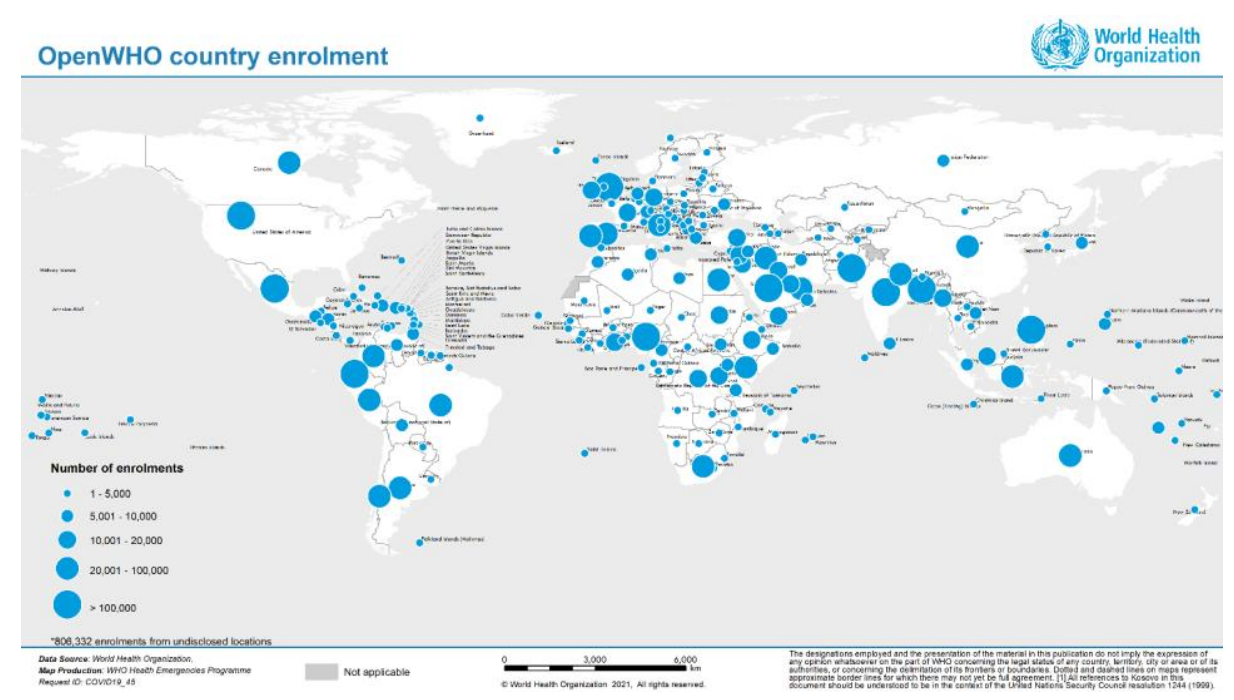

Fig. 2. OpenWHO country enrolment by countries as of March 2021 global data

Low- and middle-income access has been shifting over the pandemic when comparing December 2019 and March 2021 data. Enrolments by users from low-income countries (LIC) dropped from $14.2 \%$ to $3.4 \%$, a similar trend was seen for highincome countries (HIC) dropping from $45.9 \%$ to $25.9 \%$, contrary to a spike seen for middle-income countries (MIC) users, jumping from $40.2 \%$ to $70.7 \%$ of total enrolments. Factors attributing to this phenomenon are yet to be explored.

To investigate the learner perceived accessibility issues, a survey conducted in March 2021 captured some information on the enabling factors in general. A total of 365 respondents completed the survey. The item on challenges that hinder accessing knowledge, training, or education give an indication of the likely barriers to learning. The responses suggested that top five challenges in accessing the learning were time (48\%), cost (45\%), digital access (24\%), not knowing where to access reliable source of learning materials (24\%), and language (19\%). Female respondents were twice as likely to choose time and cost compared to male respondents. The enabling factors were OpenWHO platform being easily accessible, gratis, informative, simple, and suitable for everyone. 
A survey on health worker vaccine courses also asked about the barriers to attend the course. While $56 \%$ indicated no barriers, those who had experienced barriers listed them being internet connection issues, platform or IT related, difficulty in navigating the pages, time constraint, and language barrier. Out of the most indicated barriers, the internet connectivity was an issue for the learners from Global South despite OpenWHO requirement is the low bandwidth adjusted delivery. This still needs more investment and effort in terms of reducing the access issues caused by the internet and browsing.

Feasibility. On the availability and feasibility side, the aspects of material flexibility, ease of use and intuitiveness were explored. Due to the nature of the emergency learning courses, the materials needed to be developed fast in an event of any outbreak or health emergency. The OpenWHO platform emergency learning courses consisted of three simple elements video, texts and quiz. The selection of these material formats was informed by the accessibility issues as well as the necessity to regularly revise and update parts or entire course modules. The simple formats not only worked for the learners in the low-bandwidth settings but also for the course producers who could perform the globally dispersed production independently. As a result, live courses could be revised without any downtime for the learners.

As observed in other online learning preference [51], the similar formats were offered on OpenWHO. A survey on learner preference conducted for the COVID-19 vaccination courses in March 2021, indicated that video was the most preferred format $(51.4 \%)$, followed by slides $(45.9 \%)$. The least preferred format was collaborative spaces $(12 \%)$.

Most of the courses were delivered via instructional videos on OpenWHO. This was consistent with previous research and findings from the literature review. Hébert and colleagues concluded that videos might serve as an effective and appreciated knowledge transfer and training tool for health professionals, with four key aspects being identified through qualitative data analysis: 1) transmitting information in a narrative form, 2) choosing good communicators, 3) creating a visual instrument that reinforces the message, and 4) adapting the message to the local context that reinforces the message, and 4) adapting the message to the local context [41].

Based on data on accessibility, availability and feasibility aspects in terms of languages, the workflow was to produce and publish any course in the fastest possible mode in English. The sooner the English version was produced, the translation work into other key languages from the outbreak response angle was considered and initiated. UN languages were leading as top languages on the platform: English, Spanish, French, Portuguese and Arabic followed by Indian sign language, Hindi, Indonesian. Russian and Italian (Figure 3). 


\section{OpenWHO.org - A multilingual learning platform \\ COVID-19 enrolments distribution per language available on the platform}

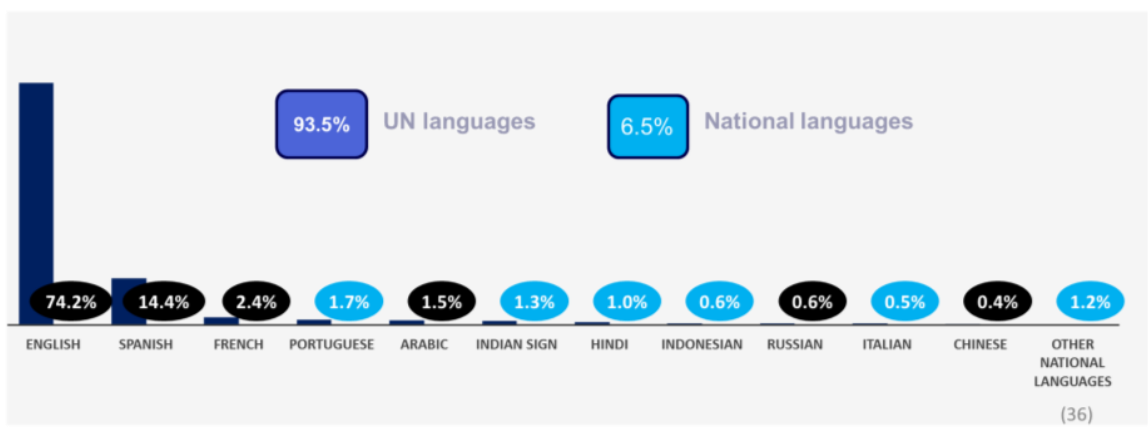

\section{4,2 Million total enrolments in COVID-19 resources}

Fig. 3. Percentage of use of languages on OpenWHO

While the UN languages counted for $93.5 \%$ of use and all other 36 languages for $6.5 \%$, it was imperative to ensure accurate information reached the frontline and public in the most vulnerable settings. Impact of language on learning outcomes is documented not only in the literature, but also in the OpenWHO surveys. In March 2021 alone, OpenWHO translated nearly 1 million words. OpenWHO continued to crowdsource and work with regions, countries and volunteers to produce courses in local languages. The language offerings currently include 14 African languages.

Targeted translation into underserviced languages was done to ensure people everywhere could access life-saving knowledge in the languages they understand. A total of 26 national language courses for low- and middle-income countries (LMICs) were translated and published during 2020-2021 so that the most disadvantaged and at-risk communities could access lifesaving information to protect themselves and their loved ones from COVID-19.

OpenWHO also adjusted the formats to suit all users including the learners with special needs. OpenWHO served people with disabilities, such as the deaf community for which the courses were offered using a sign language resource, produced an Indian sign language, but used vastly around the world by 55000 learners, with top countries India, Bangladesh, Pakistan, Saudi Arabia and Iraq.

OpenWHO and learning equity. The user group 70+ years was not represented before the pandemic, but it increased to $4.59 \%$ of learners during the pandemic. The age group less than 20 years grew from $1.26 \%$ to $9.77 \%$ representing the biggest increase and change from before the pandemic.

The COVID-19 pandemic has increasingly brought more women to learn on the OpenWHO.org platform. Platform average showed the number of women participants grew from $40.14 \%$ before the pandemic to slightly more than $50.63 \%$ currently. Whereas prior the pandemic, $70-80 \%$ of learners in courses were men, during the pandemic the learner enrolment was almost equal between women and men with 
some courses like the Infection Prevention and Control being led by female learners. Women had lower representation $(43.10 \%)$ on non-COVID-19 courses suggesting the pandemic has equalized attendance to online learning.

Students as learners represent $38.30 \%$ of the enrolments, totaling 1.9 million enrolments. Health professionals are the second largest group enrolled on COVID-19 courses accounting for $23.70 \%$ of total enrolments. In the health worker vaccine course, the health-related affiliations were much more common counting to $67.30 \%$.

With regards to the motivation for completing the courses, OpenWHO surveys indicated career and educational purposes being at the forefront. These were the cases of health worker vaccine courses, for which the most frequent reason $(35.3 \%)$ was career, followed by certification (11.4\%), education (11.2\%) and mandated learning $(3.1 \%)$. For Ebola e-Protect, the reasons for having attended the course were compulsory requirements $(33.4 \%)$, increased knowledge about the disease $(30.2 \%)$, protecting oneself from the disease $(25.7 \%)$ and strengthening the future employment or assignment qualifications $(10.3 \%)$.

\section{Discussion}

The digital transformation of WHO's technical guidance and evidence into online learning formats was in a high demand. The speed of production of learning content and scalability of OpenWHO platform itself responded to the pandemic learning need from all over the world [59]. The dynamic learning environment created lead to and facilitated a worldwide frontline response to the pandemic, worked for the purpose it was developed in a real time test. This was the first time in WHO's history that the organization was able to launch fast, high-quality, accessible learning on a massive scale to manage a health threat. While the platform served front-line responders in previous outbreaks from Ebola to plague, 2020 marked its first pandemic test. The platform has successfully delivered learning responses since January 2020. OpenWHO built on the collaborative systems already in place to quickly and dramatically scale up course production for the pandemic, making life-saving information from WHO experts available online at a time when lockdowns and social distancing limited our ability to be physically present to learn. The platform was adjusted for lowbandwidth, massive scale, easy to produce and multi-device formats to use and thus works for greater global reach.

OpenWHO is grounded in the principles of open access and equity, courses are free, self-paced, accessible in low-bandwidth and offline formats and adjusted to multi-device use. The foundational principle lays on removing all possible barriers for learners to join. Information and learning material provision is adjusted to mass dissemination modes and the asynchronous learning format offers the materials accessible at any time.

The learning content relies on the WHO's evidence and science, norms and standards and are frequently updated to implement the changes occurring to the technical guidance documents to be revised on learning content. 
Reliable and up-to-date information is essential to the pandemic response and therefore regularly updated online content is needed as the new scientific and technical guidance becomes available. For example, in December 2020, the platform expedited the production of two COVID-19 vaccination courses - one for training health workers and other on national deployment and vaccination planning - to provide local, national and global stakeholders with critical information ahead of vaccination rollouts. Meanwhile, OpenWHO's introductory course on COVID-19, published in January 2020, has been updated 13 times to reflect the latest evidence and has more than one million enrolments. The platform continues to add around $2000-$ 3800 new learner enrolments a day making learning content available to people all over the world.

Pedagogical approaches used for OpenWHO courses were aligned with existing research on digital learning to enhance knowledge transfer. As indicated in the review of literature, digital learning approaches were found to be more effective to improve knowledge level of public health professionals [17-20, 43, 44, 48, 49]. In addition, several studies called for a need to develop digital learning standards to provide effective learning. Accordingly, the design and development of courses on OpenWHO followed evidence-based learning design standards. These include learning design based on inclusive pedagogy, equity, feasibility, and accessibility with regard to age, disabilities, and technical limitations such as low-bandwidth internet connection [27, 44, 46, 54].

Per review of literature, lack of access to credible and up-to-date information can be a barrier in digital learning for health professionals [24]. Having access to timely and accessible information during a global pandemic should be primary considerations in design and development of digital learning [24-26, 40]. This was closely observed in OpenWHO by ensure evidence-based and up-to-date learning material are provided to health workers and to any interested learners. While OpenWHO performs as a "knowledge broker" to disseminate WHO's evidence-based information, next steps would need to be taken by learners and stakeholders to maximize knowledge multiplication, localization and learning transfer also outside the platform premise.

The accessibility, availability, and feasibility of digital learning was explored based on literature provided enabling aspects such as cost saving, ease of use and digital inclusion [9, 27, 36, 44, 46, 47, 50, 54, 55]. Unlimited access, self-directive learning experience and intuitive use of materials were important for digital inclusion as well as adaptivity for different populations such as working adults [27, 44, 46, 54]. While some of the online learning aspects, such as the interactivity, are not a stronghold on OpenWHO, they were knowingly not utilized to ensure the widest possible accessibility.

OpenWHO helped to enhance health literacy as part of the global effort to fight the COVID-19 pandemic and this could be witnessed from the enrolments by different less represented age groups prior to the pandemic. Older people were more vulnerable to the COVID-19 disease and had actively sought life-saving information.

The barriers were found varying from digital literacy, to language and technical capacity $[47,50,55]$ to internet access and quality of Internet connection and other 
technical difficulties [9, 46, 55]. Vision problems of learners are also listed [25] and being addressed on OpenWHO by providing audio and all downloadable versions.

OpenWHO.org was designed with equity, access, and quality in mind. First, the cost barriers were removed by offering free courses. Next, considering the digital divide, the platform offered low-bandwidth and offline versions with the OpenWHO application. The accessibility and uptake were increased by offering learning in an ever-growing number of languages. Informed decisions were made to provide a multiple format such audio, video, readable transcripts, and resource handouts. This is aligned with universal design for learning (UDL), in which the learner has the option to use the format that works for them. Quality was ensured by applying adult learning science to the design and delivery of courses using content from evidence-based WHO guidance approved by WHO experts. The key elements for reaching the impact through the online learning interventions in a health emergency are shown in Figure 4.

-)) Key elements for online knowledge and learning transfer interventions at scale

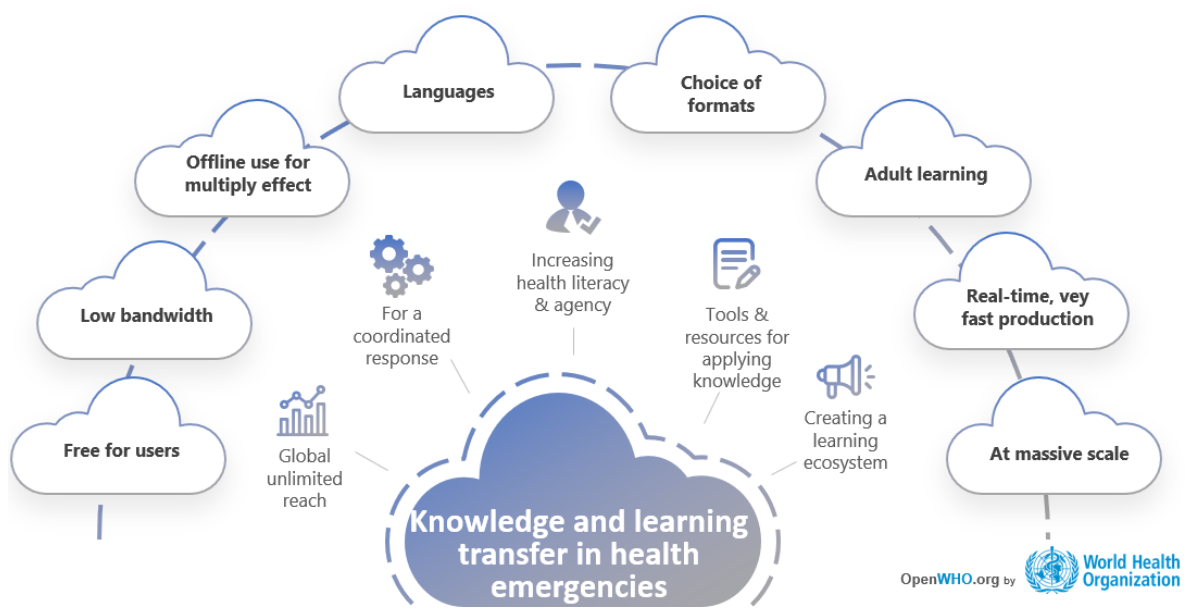

Fig. 4. Key elements for online knowledge and learning transfer at scale during health emergencies

Aligned with research in the review of literature, WHO ensured that all learning materials on OpenWHO were accessible by all learners who enrolled in the courses regardless of their technology and language by capitalizing on strengths of asynchronous learning $[2,5]$. In addition, employing best practices in line with adult learning principles and learning science during content creation, and providing easy-tounderstand content led to an increase of enrolment on OpenWHO by both health professionals and general public [24-27].

OpenWHO was designed to allow a small team to develop and launch courses within a short period of time; the content could be updated by the same team as new knowledge evolved as is the reality during a pandemic. The technology used for the platform also allowed massive scale up. 
Paper-Online Learning for Mass Audiences during the COVID-19 Pandemic: Key Considerations for..

This paper illustrates how evidence-based knowledge may inform the practice of real-time knowledge transfer in the emergency context.

\section{Conclusions}

The COVID-19 online learning response has shown to be important action to protect one's and one another's' health in a pandemic. Access to updated evidence-based information is an essential need for all populations affected by a health emergency. Hence, barriers to accessing learning must be proactively and knowingly eliminated.

Latest during the COVID-19 pandemic the real-time learning has become a core element of a response to a health emergency. COVID-19 requires continued innovation and focus on equitable learning. It calls for harnessing new technology, scaling up course production and ensuring that formats, dissemination channels and languages suit the learners.

As online learning environments continue to respond to remote and self-paced learning needs, parallel demands are there to move from knowledge change to wider behavior change, from asynchronous to synchronous learning formats when feasible and necessary for the desired learning outcomes, allow moderated and interactive formats to complement the self-paced online learning, and further, to allow countryoriginated and localized materials to be curated to local needs.

Overall, equity must be the underlying principle and organizing criteria for all the work in public health including in learning. Without equity in access to knowledge and education, there can be no access to health and better health outcomes, and this is the case when protecting individuals and populations in public health emergencies.

Online learning interventions can contribute to globally equitable and available reach, keep the response coordinated, increase health literacy among the populations and provide agency to act. Further, the sound and solid learning base provides tools for learners to apply the knowledge in their contexts. As a major outcome, the rightly focused and disseminated knowledge and learning interventions foster and support the creation of learning ecosystems appropriated for the topic, place, and time.

\section{$6 \quad$ Limitations and future work}

Limitations of the review laminations: The literature review had potential limitations. One such limitation was the search period of studies, i.e., selecting research studies within 2019 and 2020. The rationale for this was to focus on OpenWHO initiative and any emerging studies as a result of the global pandemic. Standard review processes were followed; however, they were time restricted, thereby reducing their thoroughness.

Limitations of the OpenWHO data: The descriptive nature of OpenWHO data did not allow us to determine causal relationships. Additionally, we used both platform overall statistics and self-reported data, the latter risking to result in some response bias. We also acknowledge the limitations of the non-randomized online data, which may result in some bias. 
Future research: To truly harness the power of online learning beyond COVID-19 we need to address the question on how to go beyond knowledge transfer and build online learning with larger emphasis on skills delivery against set competencies. Evaluating the efficacy and impact of online learning will be the most critical question for anyone involved in learning across the health response and international systems in the pandemic response. Financial attributions related to the online learning, the impact of the environmental factors, as well as the use of online learning in lowincome countries calls for more specific research, both within the OpenWHO context but also beyond.

\section{$7 \quad$ Acknowledgements}

Learning and Capacity Development (LCD) Unit, OpenWHO team and in particular, Ngouille Ndiaye, Corentin Piroux, Mafalda Dancante, Paula Christen, Melissa Attias and Chelsea Brown.

\section{References}

[1] The World Economic Forum website. The COVID-19 pandemic has changed education forever. Accessed: September, 23, 2021; Available from: https://www.weforum.org/agenda/ 2020/04/coronavirus-education-global-covid19-online-digital-learning/

[2] Zhao Y, and Watterston J. The changes we need: Education post COVID-19. Journal of Educational Change volume. 2021; 22:3-12. https://doi.org/10.1007/s10833-021-09417-3

[3] The World Health Organization, the University of Melbourne, Wunderman Thomson, and Pollfish. Social Media \& COVID-19: A Global Study of Digital Crisis Interaction among Gen Z and Millennials Key Insights. 2021.

[4] Launois P, Maher D, Certain E, Ross E, Penkunas MJ. Implementation Research Training for Learners in Low- and Middle-Income Countries Evaluating Behavior Change after Participating in A Massive Online Open Course.Translational Medicine. 2021; 59. https://doi. org/10.21203/rs.3.rs-78226/v1

[5] Darras KE, Spouge RJ, de Bruin ABH, Sedlic A, Hague C, Forster BB. Undergraduate Radiology Education During the COVID-19 Pandemic: A Review of Teaching and Learning Strategies. Can Assoc Radiol Journal. 2021; 72:2. https://doi.org/10.1177/084653712094482 $\underline{1}$

[6] Kirwan C, and Ebrary Inc. Improving learning transfer a guide to getting more out of what you put into your training. 2008; Aldershot, Hants, England; Burlington, VT: Ashgate.

[7] Yanmill S, and McLean GN. Theories supporting transfer of training. Human Resource Development Quarterly. 2001; 2:2. https://doi.org/10.1002/hrdq.7

[8] Baldwin TT and Ford JK. Transfer of training: A review and directions for future research. Personnel Psychology. 1988; 41(1):63-105. https://doi.org/10.1111/j.1744-6570.1988.tb0063 $\underline{2 . x}$

[9] Saks AM, and Burke LA. 2Communicating risk in public health emergencies: a WHO guideline for emergency risk communication (ERC) policy and practice World Health Organization 012. An investigation into the relationship between training evaluation and the transfer of training. International Journal of Training and Development.2012. https://doi.org/ 10.1111/j.1468-2419.2011.00397.x 
[10] Baldwin T, Ford K, and Blume, B. The state of transfer of training research: Moving toward more consumer-centric inquiry. Human Resource Development Quarterly. 2017; 28:1. https:/ /doi.org/10.1002/hrdq.21278

[11] Blume B, Ford K, Baldwin T, and Huang, J. Transfer of training: A meta-analysis. Journal of Management. 2010; 36:4. https://doi.org/10.1177/0149206309352880

[12] Liu Q, Peng W, Zhang F, Hu R, Li Y, Yan, W. The effectiveness of blended learning in health professions. Journal of Medical Internet Research. 2016;18: 1. https://doi.org/10.2196/ imir.4807

[13] Vallée A, Blacher J, Cariou A, Sorbets E. Blended learning compared to traditional learning in medical education: Systematic review and meta-analysis. Journal of Medical Internet Research. 2020; 22:8. https://doi.org/10.2196/16504

[14] Li C, He J, Yuan C, Chen B, Sun Z. The effects of blended learning on knowledge, skills, and satisfaction in nursing students: A meta-analysis. Nurse Education Today. 2019; 82: 5157. https://doi.org/10.1016/j.nedt.2019.08.004

[15] Yigzaw M, Tebekaw Y, Kim Y, Kols A, Ayalew F, EyassuG. Comparing the effectiveness of a blended learning approach for basic emergency obstetric and newborn care training in Ethiopia. Midwifery. 2019; 78:42-49. https://doi.org/10.1016/j.midw.2019.07.014

[16] Milanese S, Grimmer-Somers K, Souvlis T, Innes-Walker K, Chipchase L. Is a blended learning approach effective for learning in allied health clinicians? Physical Therapy Reviews. 2014; 19:2. https://doi.org/10.1179/1743288X13Y.0000000113

[17] Malony S, Nicklen P, Rivers G, Foo J, Oui Y, Reeves S, Illic D. A cost-effectiveness analysis of blended versus face-to-face delivery of evidence-based medicine to medical students. Journal of Medical Internet Research. 2015; 17:7. https://doi.org/10.2196/jmir.4346

[18] Annand D. Learning efficacy and cost-effectiveness of print versus e-book instructional material in an introductory financial accounting course. Journal of Interactive Online Learning.2008; 7:2.

[19] Aldohyan M, Al-Rawashdeh, Sakr MF, Rahman S, Alfarhan AI, Salam M. The perceived effectiveness of MERS-CoV educational programs and knowledge transfer among primary healthcare workers: a cross-sectional survey. BMC Infectious Diseases. 2019;19:273. https:// doi.org/10.1186/s12879-019-3898-2

[20] Fernandez-Diaz E, Iglesias-Sanchez PP, and Jambrino-Maldonado C. Exploring WHO Communication during the COVID 19 Pandemic through the WHO Website Based on W3C Guidelines: Accessible for All? International journal of environmental research and public health. 2020;17(16): p. 5663. https://doi.org/10.3390/ijerph17165663

[21] Chick R, Clifton GT, Peace KM, Propper BW, Hale DF, Alseidi AA. Using Technology to Maintain the Education of Residents During the COVID-19 Pandemic. Journal of Surgical Education. 2020; 77(4): p. 729-732. https://doi.org/10.1016/j.jsurg.2020.03.018

[22] Zitzmann NU, Matthisson L, Ohla H, and Joda T. Digital Undergraduate Education in Dentistry: A Systematic Review. INTERNATIONAL JOURNAL OF ENVIRONMENTAL RESEARCH AND PUBLIC HEALTH. 2020; 17(9): p. 3269. https://doi.org/10.3390/ijerph1 7093269

[23] Butler-Henderson K, Crawford J, Rudolph J, Lalani K and Sabu KM. COVID-19 in Higher Education Literature Database (CHELD V1): An open access systematic literature review database with coding rules. Journal of Applied Learning \& Teaching. 2020; 3(2): p. 1-6. https://doi.org/10.37074/jalt.2020.3.2.11

[24] Dedeilia A, Sotiropoulos GM, Hanrahan JG, Deepa J, Panagiotis D, Sideris M. Medical and Surgical Education Challenges and Innovations in the COVID-19 Era: A Systematic Review. In VIVO. 2020; 343(3): p. 1603-1611. https://doi.org/10.21873/invivo.11950 
[25] Edgerton AK, Cookso PW. Closing the Digital Divide: The Critical Role of the Federal Government. 2020. Accessed: Spetember, 23, 2021; Available from: https://learningpolicy institute.org/blog/covid-closing-digital-divide-federal-government

[26] Ratten V. Coronavirus (covid-19) and social value co-creation. International Journal of Sociology and Social Policy 2020. ahead-of-print. https://doi.org/10.1108/IJSSP-06-2020-0237

[27] Moonen G. The Privilege of being a resident during COVID-19. 2020. Accessed: Spetember, 23, 2021; Available from: http://cmajblogs.com/the-privilege-of-being-a-resident-during -covid-19/

[28] Koumpouras F, and Helfgott S. Stand Together and Deliver: Challenges and Opportunities for Rheumatology Education During the COVID-19 Pandemic. Arthritis \& Rheumatology. 2020; 72(7):1064-1066. https://doi.org/10.1002/art.41278

[29] Nassar AH, Zern NK, Mcintyre LK. Emergency Restructuring of a General Surgery Residency Program During the Coronavirus Disease 2019 Pandemic: The University of Washington Experience. JAMA Surg. 2020;155(7): p. 624-627. https://doi.org/10.1001/jamasurg. 2020.1219

[30] Potts JR. Residency and Fellowship Program Accreditation: Effects of the Novel Coronavirus (COVID-19) Pandemic. Journal of the American College of Surgeons. 2020; 230(6):1094-1097. https://doi.org/10.1016/j.jamcollsurg.2020.03.026

[31] Tretter JT, Windram J, Faulkner T, Hudgens M. et al. Heart University: a new online educational forum in paediatric and adult congenital cardiac care. The future of virtual learning in a post-pandemic world? Cardiology in the Young. 2020; 30(4):560-567. https://doi.org/10.10 17/S1047951120000852

[32] Alvin MD, George E, Deng F, Warhadpande S, Lee SI. The Impact of COVID-19 on Radiology Trainees. Radiology. 2020; 296(2): 246-248. https://doi.org/10.1148/radiol.202020122 $\underline{2}$

[33] Sentell T, Vamos S, Okan O. Interdisciplinary Perspectives on Health Literacy Research Around the World: More Important Than Ever in a Time of COVID-19. Int. J. Environ. Res. Public Health. 2020; 17:9. https://doi.org/10.3390/ijerph17093010

[34] White H. Reshaping education: evidence-based options for a post-Covid-19 world. Accessed: Spetember, 23, 2021; Available from: https://www.campbellcollaboration.org/blog/ education-evidence-based-options-post-covid-19.html

[35] Chang Liang Z, Beng Suat Ooi S, Wang W. Pandemics and Their Impact on Medical Training: Lessons from Singapore. Academic Medicine. 2020; 95:9. https://doi.org/10.1097/ACM .0000000000003441

[36] Hébert C, Dagenais C, Mc Sween-Cadieux E, Ridde V. Video as a public health knowledge transfer tool in Burkina Faso: A mixed evaluation comparing three narrative genres. PLOS Neglected Tropical Diseases. 2020; 14:6. https://doi.org/10.1371/journal.pntd.0008305

[37] Provvidenza C, Townley A, Wincentak J, Peacocke S, Kingsnorth S. Building knowledge translation competency in a community-based hospital: a practice-informed curriculum for healthcare providers, researchers, and leadership. Implement Sci. 2020;15(1):54. https://doi. org/10.1186/s13012-020-01013-y

[38] Brown A, Barnes C, Byaruhanga J, McLaughlin M, Hodder KR, Booth D, et al. Effectiveness of Technology-Enabled Knowledge Translation Strategies in Improving the Use of Research in Public Health: Systematic Review. J Med Internet Res. 2020;22(7): p. e17274. https://doi.org/10.2196/17274

[39] Martinengo L, YingYeo NJ, Markandran K, Olsson M, Myint Kyaw B, Tudor Car L. Digital health professions education on chronic wound management: a systematic review. International journal of nursing studies,. 2020; 104: p. 103512. https://doi.org/10.1016/j.ijnurstu.2 $\underline{019.103512}$ 
[40] Nagendran M, Chen Y, Lovejoy CA, Gordon AC, Komorowski M, Harvey H, Topol JE, Ioannidis JPA, Maruthappu M. Artificial intelligence versus clinicians: systematic review of design, reporting standards, and claims of deep learning studies. BMJ. 2020; 368: p. m689. https://doi.org/10.1136/bmj.m689

[41] Regmi K, and Jones L. A systematic review of the factors - enablers and barriers - affecting e-learning in health sciences education. BMC Med Educ. 2020; 20(1): p. 91. https://doi.org/1 0.1186/s12909-020-02007-6

[42] Sadoughi F, Ali O, and Erfannia L. Evaluating the factors that influence cloud technology adoption-comparative case analysis of health and non-health sectors: A systematic review. Health Informatics J. 2019; 26(2): p. 1363-1391. https://doi.org/10.1177/1460458219879340

[43] Tudor Car L, Soong A, Myint Kyaw B, Chua KL, Low-Beer N, Majeed A. Health professions digital education on clinical practice guidelines: a systematic review by Digital Health Education collaboration. BMC medicine. 2019; 17(1): p. 139-16. https://doi.org/10.1186/s12 916-019-1370-1

[44] Vaona A, Banzi R, Kwag KH, Rigon G, Cereda D, Pecoraro V, Tramacere I, Moja L. Elearning for health professionals. Cochrane Database of Systematic Reviews. 2018;1(1): CD011736. https://doi.org/10.1002/14651858.CD011736.pub2

[45] Taylor MJ, Shikaislami C, McNicholas C, Taylor D, Reed J, Vlaev I. Using virtual worlds as a platform for collaborative meetings in healthcare: a feasibility study. Login BMC Health Services Research. 2020; 20:442. https://doi.org/10.1186/s12913-020-05290-7

[46] Wahito Nugroho HS, Handoyo H, Prayitno H, Budiono A. Sort Elements Based on Priority, in order to Improve the Quality of E-Learning in Health Using Difficulty-Usefulness Pyramid with Weighting (DUP-We). International Journal of Emerging Technologies in Learning (iJET). 2019; 14:18. https://doi.org/10.3991/ijet.v14i18.10809

[47] Colaceci S, Zambri F, D'Amore C, De Angelis A, Rasi F, Pucciarelli G, Giusti A. LongTerm Effectiveness of an E-Learning Program in Improving Health Care Professionals' Attitudes and Practices on Breastfeeding: A 1-Year Follow-Up Study. Breastfeeding Medicine. 2020; 15:4. https://doi.org/10.1089/bfm.2019.0203

[48] Maier A, Hoffmann U, Fegert JM. Child protection in medicine - closing gaps in continuing education through e-learning. The European Journal of Public Health. 2019; 29:11. https://do i.org/10.1093/eurpub/ckz186.567

[49] Carapeto C, and Barros DMV. Nutrition and health as virtual class at Open University (Portugal): pedagogical strategies for higher education. International Journal of Educational Technology in Higher Education volume. 2019; 16. https://doi.org/10.1186/s41239-019-015 $\underline{1-4}$

[50] Burkardt AD, Krause N, and Rivas Velarde MC. Critical success factors for the implementation and adoption of e-learning for junior health care workers in Dadaab refugee camp Kenya. Hum Resour Health. 2019;17(1): p. 98. https://doi.org/10.1186/s12960-019-0435-8

[51] Salas E, Tannenbaum S, Kraiger K, Smith-Jentsch K. The Science of Training and Development in Organizations: What matters in practice. Psychological Science in the Public Interest.2012; 13(2): 74-101. https://doi.org/10.1177/1529100612436661

[52] Salas E, Milham L, \& Bowers C. Training evaluation in the military: Misconceptions, opportunities, and challenges. Military Psychology. 2003; 15(1): 3-16. https://doi.org/10.1207/S15 327876MP1501_01

[53] Utunen H, Van Kerkhove MD, Tokar A, O'Connell G, Gamhewage GM, Fall IS. One year of pandemic learning response: Benefits of massive online delivery of World Health Organization's technical guidance. JMIR Public Health Surveill. 2021. https://doi.org/10.2196/28945

[54] Utunen H, George R, Ndiaye N, Attias M, Piroux C, Gamhewage G. Responding to global learning needs during a pandemic: an analysis of the trends in a WHO MOOC platform use 
Paper _ Online Learning for Mass Audiences during the COVID-19 Pandemic: Key Considerations for..

and incidence of COVID-19. Journal of Education Science. 2020; 10(11):345. https://doi.org /10.3390/educsci10110345

[55] Goldin S, So Yeon JK, Tokar A, Utunen H, Ndiaye N, Bahl J, Appuhamy R, Moen A. Learning from a massive open online COVID-19 vaccination training experience(pre-print). JMIR. 2021. https://doi.org/10.2196/preprints.33455

[56] Lehane E, Leahy-Warren P, O'Riordan C, Savage E, Drennan J, O'Tuathaigh C, O'Connor M, Corrigan M, Burke F, Hayes M, Lynch H, Sahm L, Heffernan E, et al. Evidence-based practice education for healthcare professions: an expert view. BMJ. 2019; 24:103-108. https: //doi.org/10.1136/bmjebm-2018-111019

\section{Authors}

Heini Utunen, (Equal contribution) MA, Acting Unit Head, Learning and Capacity Development Unit, WHO Health Emergencies Program, Organization Mondiale de la Santé, 20 Avenue Appia, CH-1211 Genève, Suisse, tel.: +41 227912919 (email: utunenh@who.int, ORCID: 0000-0002-0509-5067).

Anna Tokar, (Equal contribution) $\mathrm{PhD}, \mathrm{MPH}$, Consultant, Learning and Capacity Development Unit, WHO Health Emergencies Program, Organization Mondiale de la Santé, 20 Avenue Appia, CH-1211 Genève, Suisse, tel.: +34656756562 (email: tokara@who.int, ORCID: 0000-0003-4992-6819).

Elham Arabi, PhD, Learning Consultant, Learning and Capacity Development Unit, WHO Health Emergencies Program, Organization Mondiale de la Santé, 20 Avenue Appia, CH-1211 Genève, Suisse, tel.: +34656756562 (email: arabim@who. int , ORCID: 0000-0002-1686-2778).

Dr Gaya Manori Gamhewage, MD, Acting Director, Prevention and Response to Sexual Exploitation Abuse and Harassment, Organization Mondiale de la Santé, 20 Avenue Appia, CH-1211 Genève, Suisse, tel.: +41 227914030 (email: gamhewageg @who.int, ORCID: 0000-0003-2536-9173).

Article submitted 2021-10-15. Resubmitted 2021-11-19. Final acceptance 2021-12-01. Final version published as submitted by the authors. 